\title{
An eukaryotic elongation factor 2 from Medicago falcata (MfEF2) confers cold tolerance
}

\author{
Haifan Shi', Sijian $\mathrm{He}^{2}$, Xueying $\mathrm{He}^{2}$, Shaoyun $\mathrm{Lu}^{2}$ and Zhenfei Guo ${ }^{1^{*}}$ (D)
}

\begin{abstract}
Background: An eukaryotic translation elongation factor-2 (eEF-2) plays an important role in protein synthesis, however, investigation on its role in abiotic stress responses is limited. A cold responsive eEF2 named as MfEF2 was isolated from yellow-flowered alfalfa [Medicago sativa subsp. falcata (L.) Arcang, thereafter M. falcata], a forage legume with great cold tolerance, and transgenic tobacco (Nicotiana tabacum L.) plants overexpressing MfEF2 were analyzed in cold tolerance and proteomic profiling was conducted under low temperature in this study.

Results: MFEF2 transcript was induced and peaked at $24 \mathrm{~h}$ and remained at the high level during cold treatment up to $96 \mathrm{~h}$. Overexpression of MfEF2 in trasngenic tobacco plants resulted in enhanced cold tolerance. Compared to the wild type, transgenic plants showed higher survival rate after freezing treatment, higher levels of net photosynthetic rate $(A)$, maximum photochemical efciency of photosystem (PS) II $\left(F_{\mathrm{v}} / F_{\mathrm{m}}\right)$ and nonphotochemical quenching (NPQ) and lower levels of ion leakage and reactive oxygen species (ROS) production after chilling treatment. iTRAQ-based quantitative proteomic analysis identified 336 differentially expressed proteins (DEPs) from leaves of one transgenic line versus the wild type after chilling treatment for $48 \mathrm{~h}$. GO and KEGG enrichment were conducted for analysis of the major biological process, cellular component, molecular function, and pathways of the DEPs involving in. It is interesting that many down-regulated DEPs were grouped into "photosynthesis" and "photosynthesis-antenna", such as subunits of PSI and PSIl as well as light harvesting chlorophyll protein complex (LHC), while many up-regulated DEPs were grouped into "spliceosome".

Conclusions: The results suggest that MfEF2 confers cold tolerance through regulating hundreds of proteins synthesis under low temperature conditions. The elevated cold tolerance in MfEF2 transgenic plants was associated with downregulation of the subunits of PSI and PSII as well as LHC, which leads to reduced capacity for capturing sunlight and ROS production for protection of plants, and upregulation of proteins involving in splicesome, which promotes alternative splicing of pre-mRNA under low temperature.
\end{abstract}

Keywords: Cold stress, iTRAQ, Medicago falcata, MfEF2, Photosynthesis, Splicesome

\section{Background}

Low temperature is one of the major abiotic stresses that limits the distribution and productivity of crops worldwide. Many plants from temperate regions can enhance their freezing tolerance after exposure to low, non-freezing temperatures, the process was known as cold acclimation [1]. Extensive changes occur ranging from gene expression to biochemical, physiological and metabolic

\footnotetext{
* Correspondence: zfguo@njau.edu.cn

${ }^{1}$ College of Grassland Science, Nanjing Agricultural University, Nanjing 210095, China

Full list of author information is available at the end of the article
}

processes during cold acclimation [2-4]. Numerous cold-related genes such as CRT binding factor (CBF) and cold regulated (COR) genes have been identified [57]. Osmolytes and cryoprotectants, such as soluble sugars (saccharose, raffinose, trehalose), sugar alcohols (sorbitol, ribitol, inositol) and nitrogenous compounds (proline), are accumulated, and scavenging of reactive oxygen species (ROS) is activated during cold acclimation $[8,9]$.

Medicago falcata is widely distributed in the cold areas of Russia, Mongolia, Scandinavia and northern China, with great cold and drought tolerance and similar 
genetic background to alfalfa [10, 11]. It is an important gene pool for alfalfa breeding and resulted in significant heterosis for biomass yield $[12,13]$. Thus it is important to understand its mechanisms in cold tolerance and to discover new genes using for improvement of cold tolerance in crops. A serous of cold responsive genes in $M$. falcata, such as MfMIPS1 [11], MfGolS1 [14], MfINT-like [15], MfSAMS1 [16], MfTIL1 [17], and MfPIP2-7 [18], and MfERF [19], have been documented to be associated with cold tolerance. An eukaryotic elongation factor 2 encoding gene (eEF2) was found as cold responsive genes in the cDNA library of $M$. falcata using suppression subtractive hybridization (SSH) [20], implying that $e E F 2$ might be associated with cold tolerance in $M$. falcata.

Elongation factors play an important role in translation. Translation is a three-stage process comprising initiation, elongation and termination. In the peptide elongation phase of protein synthesis, elongation factor 1A transports amino acylated tRNA to the ribosome acceptor A-site, where peptidyl-tRNA is formatted, catalyzed by peptidyl transferase [21]. The pre-translocational state of the ribosome is the substrate of the GTPase EF2, which leaves a vacant A-site to allow the next aminoacyl-tRNA to enter for starting a new cycle of peptide formation [21]. Eukaryotic translation elongation factor- 2 was found to regulate rhythmic protein accumulation in Neurospora crassa [22]. Suppression of elongation is responsible for the significant reduction in global protein synthesis in mammalian cells [23]. Even though eEF2 plays an important role in protein synthesis, investigation on its role in abiotic stress responses is limited. An early study in Arabidopsis suggested that eEF2 is associated with plant cold tolerance. One point mutation in the conserved residue Cys495 of EF2 protein in Arabidopsis mutant los 1-1 blocks low temperature-induced transcription of cold-responsive genes and reduces the capacity of plants to develop freezing tolerance. Protein synthesis in los 1-1 mutant is impaired at low temperature [24]. However, it is unknown whether cold tolerance is altered in transgenic plants overexpressing $e E F 2$ gene.

In this study, a coding sequence of MfEF 2 was cloned from $M$. falcata, and transgenic tobacco plants overexpressing $M F E F 2$ were generated and analyzed. We demonstrated that MfEF2 plays an important role in plant tolerance to cold stress.

\section{Results}

\section{Cloning and characterization of MfEF2}

For analysis of MfEF2 function, a 2532 bp of open reading frame (ORF) of MfEF2 (accession no. MK125495) was cloned from leaves of cold-treated $M$. falcata plants by RT-PCR. It encodes a peptide of 843 amino acids with an estimated molecular mass of $94.25 \mathrm{kDa}$ and an isoelectric point (pI) of 5.89. Phylogenetic analysis on
EF2 from legumes and Arabidopsis showed that MfEF2 had high similarity with other plant EF2s (Fig. 1), indicating that EF2s are highly conserved evolutionarily.

\section{Response of MfEF2 expression to cold}

Transcript levels of MfEF2 in response to cold was detected using qRT-PCR. The data showed that MfEF2 transcript was induced by 3.5 -fold after 24 to $96 \mathrm{~h}$ of cold treatment, while no induction was observed within $12 \mathrm{~h}$ of treatment (Fig. 2). The result implied that MfEF2 expression might be associated with cold tolerance.

\section{Analysis of transgenic tobacco plants overexpressing MfEF2}

To confirm the function of $M f E F 2$ associated with cold tolerance, transgenic tobacco plants were produced by overexpressing MfEF2 that was driven by CaMV $35 \mathrm{~S}$ promoter. Homozygous transgenic plants were harvested by selection with kanamycin resitance from in combination with PCR assay of MfEF2. Three homozygous lines (54, 56 and 101) were chosen for analysis of DNA hybridization. Compared to no cross-hybridization signal in the wild type plants, MfEF2 was one hybridization signal was observed in each transgenic line (Fig. 3a), indicating that MfEF2 was integrated into the genomes of transgenic tobacco as one transgenic copy. Compared to the wild type, MfEF2 transcript could be detected in transgenic lines by RNA hybridization (Fig. 3b), indicating that $M f E F 2$ was expressed in transgenic plants.

\section{Analysis of freezing and chilling tolerance in transgenic plants}

Freezing tolerance was evaluated based on survival rate after exposure to $-3^{\circ} \mathrm{C}$ for $10 \mathrm{~h}$. Most of the wild type plants were dead after freezing with a survival rate of $7 \%$, while most of transgenic plants were recovered with survival rate of 54,90 , and $83 \%$ in lines 54, 56, and 101, respectively (Fig. 4a, b).

Chilling tolerance was evaluated based on ion leakage, ROS accumulation, and photosynthesis in response to low temperature. The data showed that lower levels of ion leakage and $\mathrm{H}_{2} \mathrm{O}_{2}$ accumulation were observed in transgenic plants than in the wild type after $3 \mathrm{~d}$ of chilling treatment at $2{ }^{\circ} \mathrm{C}$, while low level of $\mathrm{H}_{2} \mathrm{O}_{2}$ was detected under control condition in all plant lines (Fig. 5a, b). Higher levels of $A$ and $F_{\mathrm{v}} / F_{\mathrm{m}}$ were observed in transgenic plants than in the wild type after $3 \mathrm{~d}$ of chilling treatment at $2{ }^{\circ} \mathrm{C}$ (Fig. 6a, b). The results indicated that transgenic plants had increased freezing and chilling tolerance. Compared to no difference in $q_{\mathrm{p}}$ between transgenic plants and the wild type (Fig. 6c), higher level of $N P Q$ was observed in transgenic lines after chilling treatment (Fig. 6d). 


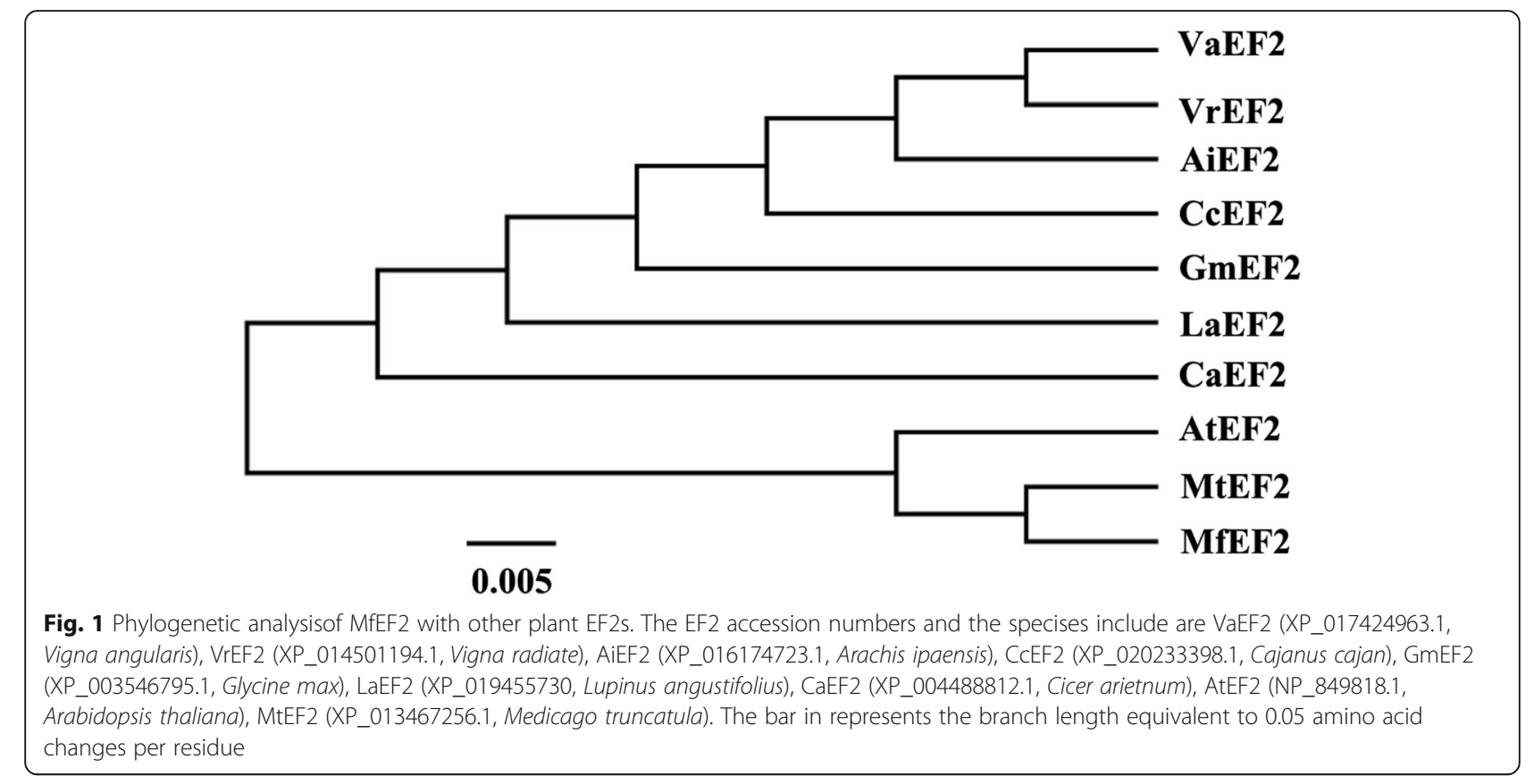

\section{Primary proteomic data analysis and protein}

\section{identification}

Given that EF2 functions in the peptide elongation phase of protein synthesis, an iTRAQ analysis was conducted to observe the proteomic difference in cold-treated leaves between a transgenic tobacco line (54) and the wild type. iTRAQ analysis of tobacco leaves generated 359,430 MS/ MS spectra. 23,855 spectra could be matched to unique peptide and 16,261 were considered as unique spectra. A total of 13,128 peptides and 2939 proteins were identified (Additional file 1: Figure S1; Additional file 2: Table S1). Most of the proteins (66.2\%) were distributed among 20 to $80 \mathrm{kDa}$, and small proteins with less than $10 \mathrm{kDa}$ were also detected (Additional file 3: Figure S2). The mass spectrometry proteomics data have been deposited to the ProteomeXchange Consortium (http://proteomecentral. proteomexchange.org) via the iProX partner repository [25] with the dataset identifier PXD011822.

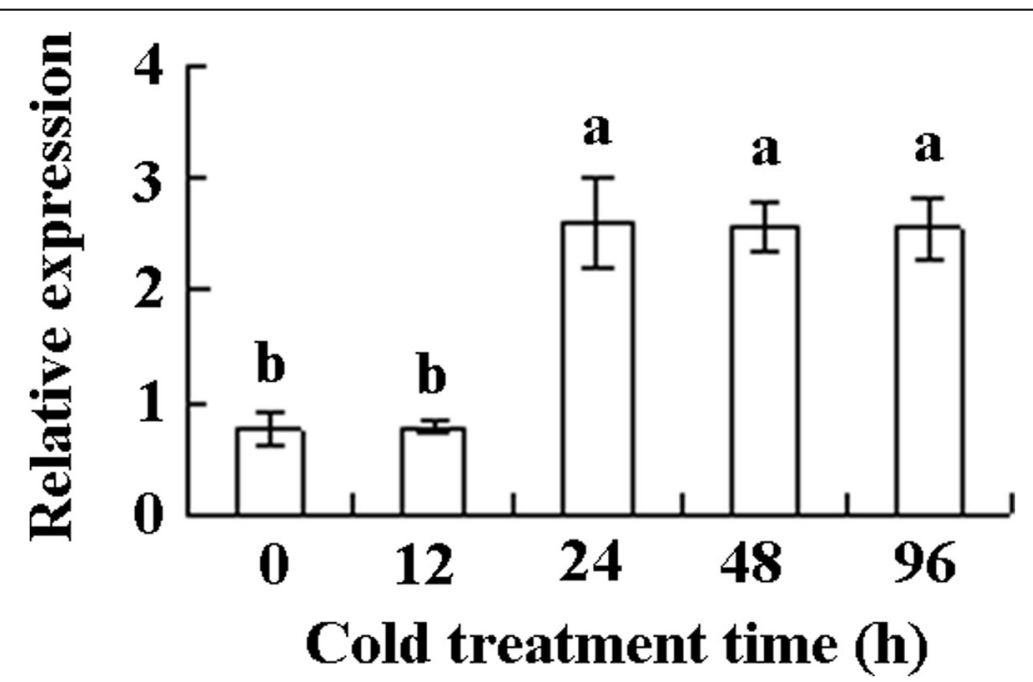

Fig. 2 MfEF2 transcript in response to low temperature. Mature leaves were sampled from pot plants treated in growth chamber at $5^{\circ} \mathrm{C}$. MfEF 2 trasncript was determined using GRT-PCR, and actin 1 was used as reference gene to normalize the amount of template. Means of three independent samples and standard errors are presented; the same letter above the column indicates no significant difference at $P<0.05$ 


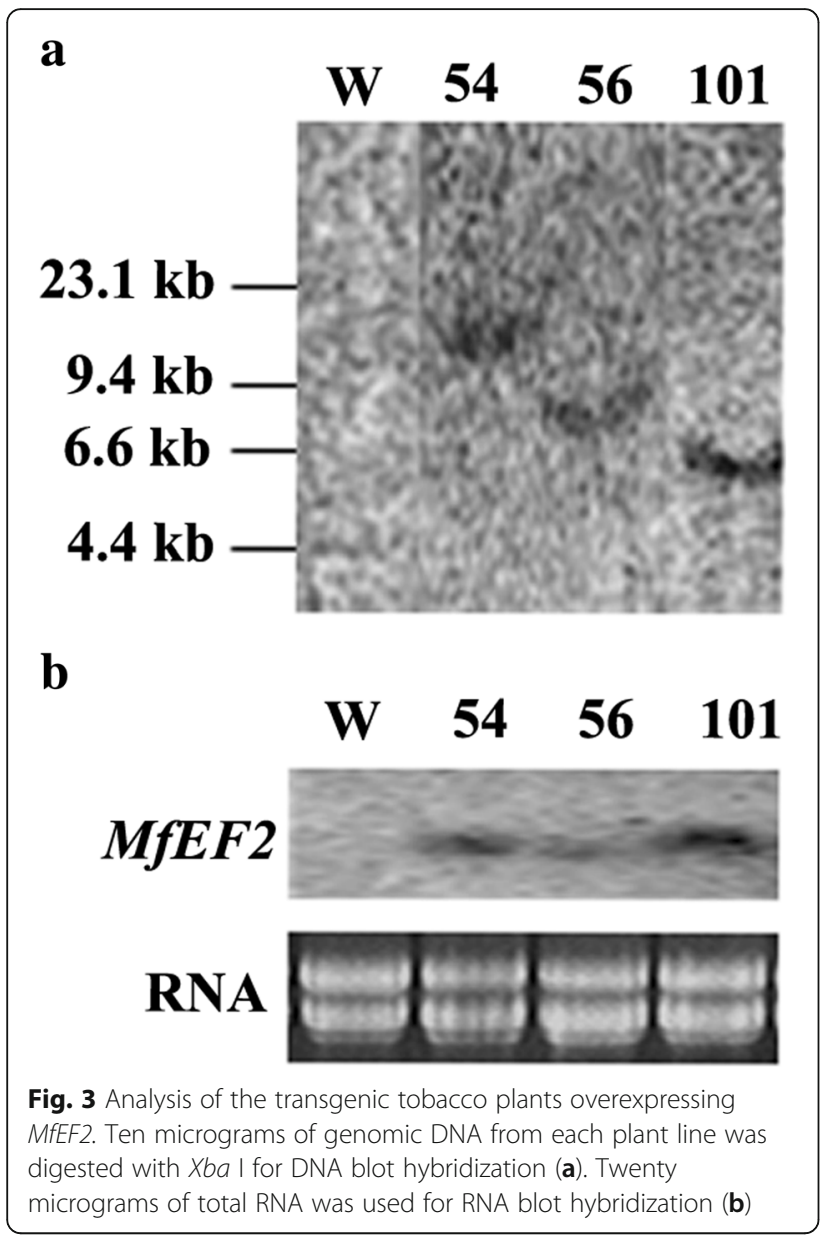

Functional classification of the differentially expressed proteins

The differentially expressed proteins (DEPs) between transgenic plant and the wild type were screened based on the standard criteria: fold-change $>1.2$ and $P$-value $<$ 0.05 . The data showed that 336 proteins including 181 up-regulated proteins and 155 down-regulated proteins were differentially expressed in transgenic tobacco as compared with the wild type after chilling treatment (Additional file 4: Table S2). Two hundred and two DEPs were classified into biological process, 269 were classified into molecular function, and 240 were classified into cellular component at GO level 2. Compared to other groups, most of the DEPs were grouped to cell process, metabolic process, single-organism process among biological process proteins; most of the DEPs were grouped to cell, cell-part, organelle, and organelle-part among cellular component proteins, and most of the DEPs were grouped to binding and catalytic activity among molecular function proteins (Fig. 7).

GO enrichment analysis of DEPs at high level were conducted to obtain more detail functional categorization. The data showed that the DEPs in biological process were mainly subgrouped to "generation of precursor metabolites and energy", "DNA duplex unwinding" and "ether metabolic process". The DEPs in molecular function were mainly subgrouped to "nucleic acid binding", "organic cyclic compound binding" and "tetrapyrrole binding". The DEPs in cellular component were subgrouped to "anchored component of membrane", "chloroplast", "chloroplast part", "endoplasmic reticulum", "endoplasmic reticulum part", "intracellular organelle part", "macromolecular complex", "membrane protein complex", "organelle subcompartment", "photosynthetic membrane", "photosystem", "plastid", "plastid thylakoid", "plastid thylakoid lumen", "protein complex", "thylakoid", "thylakoid lumen" and "thylakoid part" (Fig. 8). It is interesting that many DEPs were focused on subcellular localization associated with photosynthesis, indicating expression of MfEF2 was involved in regulation on photosynthesis.

KEGG pathway enrichment analysis was carried out for further understanding the biological functions of DEPs. There were 160 DEPs being matched to KEGG pathway

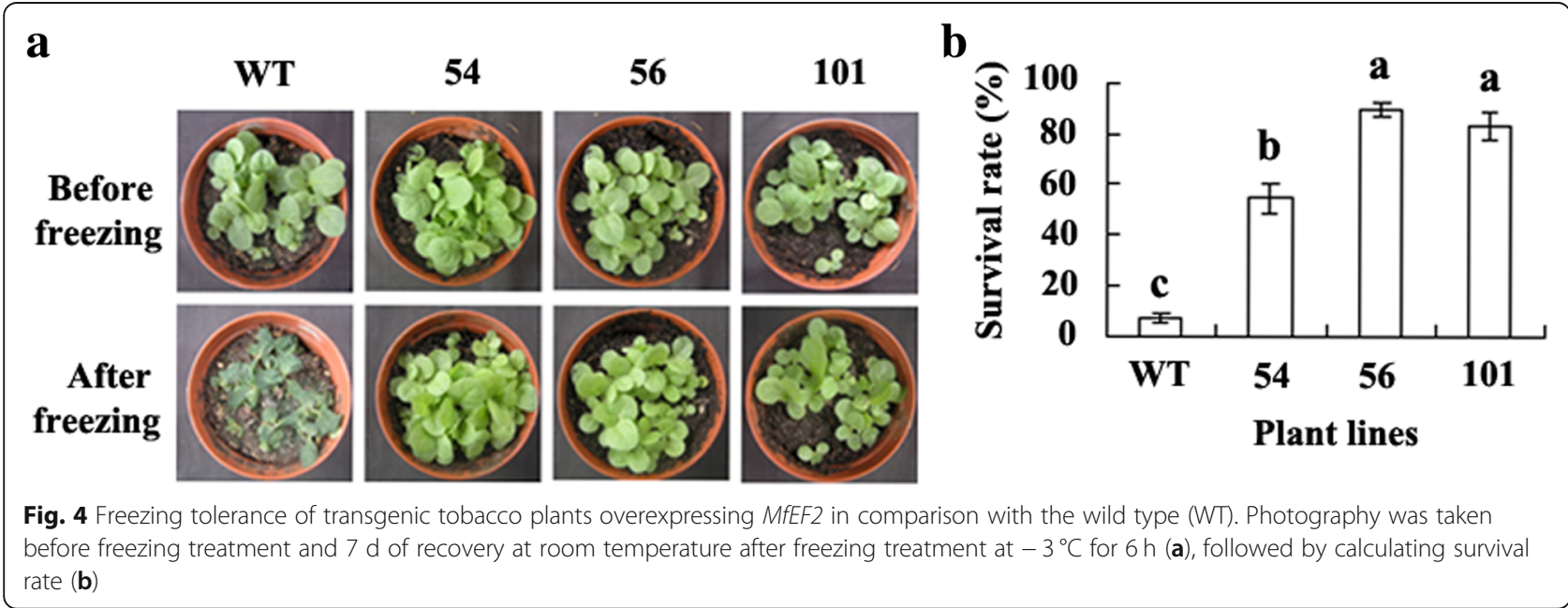




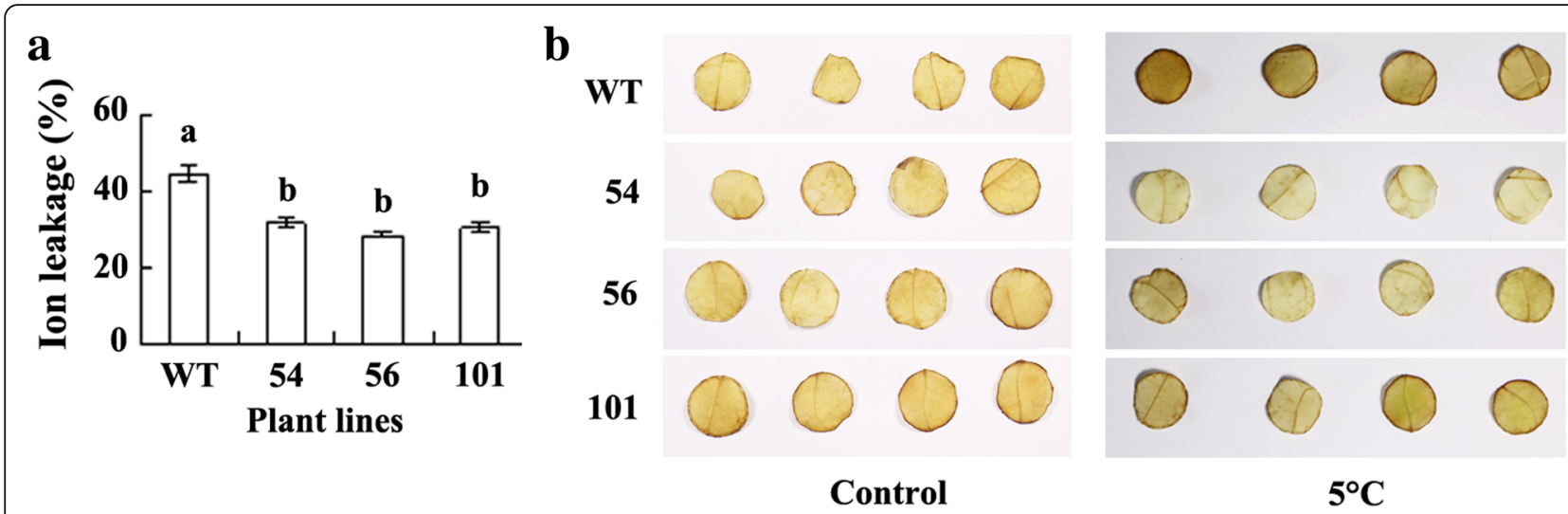

Fig. 5 lon leakage and $\mathrm{H}_{2} \mathrm{O}_{2}$ accumulation in transgenic tobacco plants overexpressing MfEF2 in comparison with the wild type (WT) after chilling treatment. Ion leakage $(\mathbf{a})$ and $\mathrm{H}_{2} \mathrm{O}_{2}$ (b) were determined $3 \mathrm{~d}$ after plants were treated at $2^{\circ} \mathrm{C}$. Means of three independent samples and standard errors are presented; the same letter above the column indicates no significant difference at $P<0.05$

including 49 signaling/metabolic pathways. Most of DEPs were significantly enriched in pathways of "photosynthesis-antenna protein", "spliceosome”, "photosynthesis","peroxisome", "ribosome", "DNA replication", "RNA transport" and "phenylpropanoid biosynthesis" (Table 1). For example, a total of 26 DEPs were involved in "photosynthesis" and "photosynthesis antenna protein". The DEPs (13) involving in "photosynthesis" pathway included one subunit of Psb27, PsaA, PetD (subunit IV of cytochrome $b_{6} f$ ), ATPF1D (delta subunit of ATP synthase), ATPF1E (epsilon subunit of ATP synthase), and ATPFOB (b subunit of ATP synthase), two subunits of PsbP and PsaG, and three subunits of PsbQ. Most of them showed down-regulated in transgenic tobacco compared with the wild type, except for PsaA which was up-regulated (Fig. 9a, b). Thirteen DEPs annotated as "photosynthesis-antenna protein" or LHC included one subunit of Lhca3, Lhca4, Lhcb1, Lhcb 3, Lhcb4 and Lhcb5, two subunits of Lhca2 and Lhcb6, and three subunits of Lhca1. All of them were down-regulated in transgenic tobacco as compared with the wild type (Fig. 10). Thirty

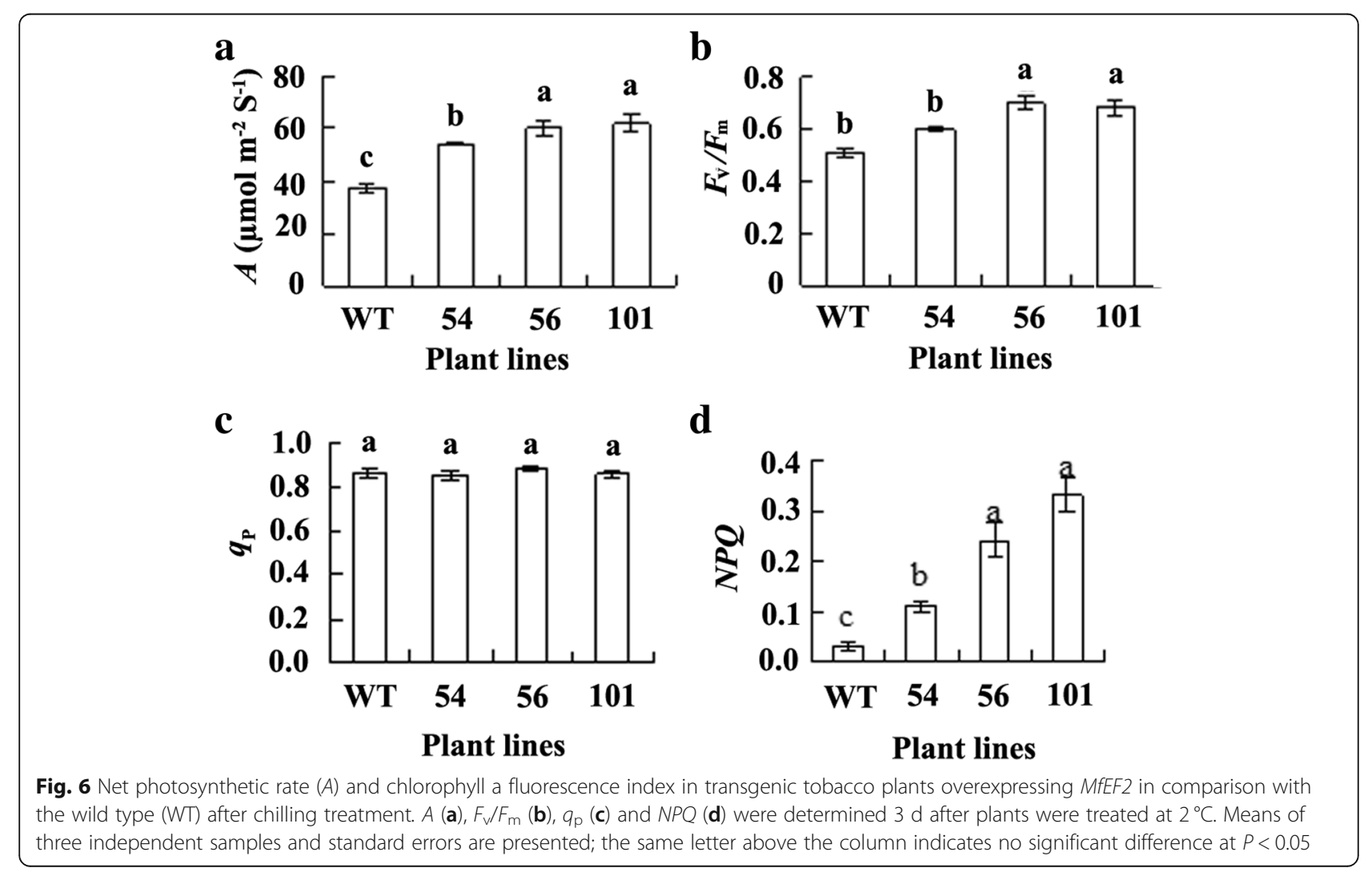



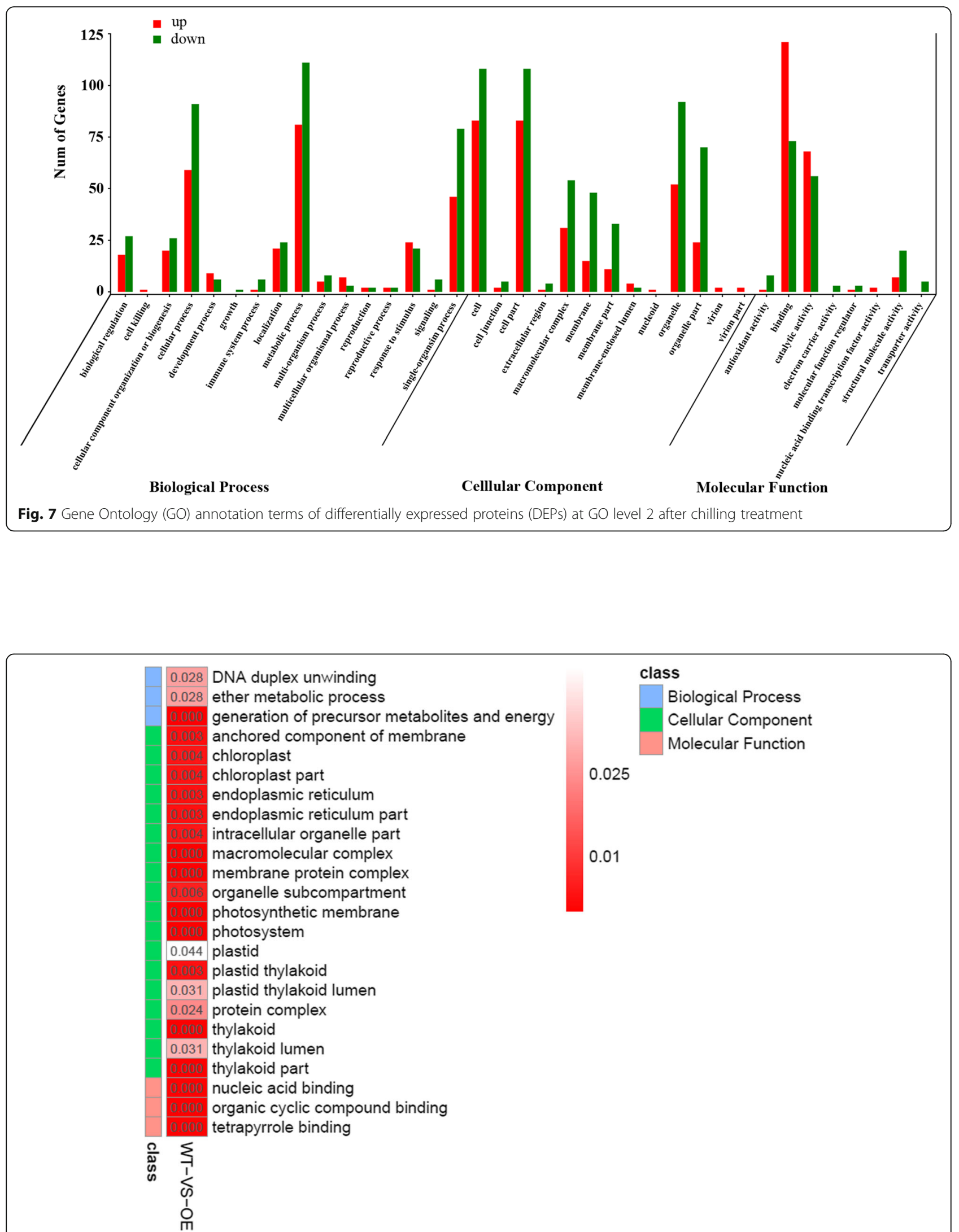

\section{class}

Biological Process

Cellular Component

Molecular Function

0.025

Fig. $8 \mathrm{GO}$ enrichment analysis of DEPs after chilling treatment 
Table 1 Significantly enriched pathways in the DEPs

\begin{tabular}{|c|c|c|c|c|}
\hline Pathway & DEPs with pathway annotation (160) & All proteins with pathway annotation (1914) & $p$-value & Pathway ID \\
\hline Photosynthesis-antenna proteins & $13(8.13 \%)$ & $15(0.78 \%)$ & 0.000000 & ko00196 \\
\hline Spliceosome & $30(18.75 \%)$ & $101(5.28 \%)$ & 0.000000 & ko03040 \\
\hline Photosynthesis & $13(8.13 \%)$ & $51(2.66 \%)$ & 0.000172 & ko00195 \\
\hline Peroxisome & $7(4.38 \%)$ & $35(1.83 \%)$ & 0.022700 & ko04146 \\
\hline Ribosome & $7(4.38 \%)$ & $214(11.18 \%)$ & 0.027091 & ko03010 \\
\hline DNA replication & $26(16.25 \%)$ & $16(0.84 \%)$ & 0.038627 & ko03030 \\
\hline RNA transport & $4(2.5 \%)$ & $84(4.39 \%)$ & 0.042792 & ko03013 \\
\hline Phenylpropanoid biosynthesis & 7 (4.38\%) & 41 (2.14\%) & 0.049751 & ko00940 \\
\hline
\end{tabular}

DEPs were grouped to "spliceosome" pathway. They belong to subunits of seven upregulated proteins including U1-70 K, p68, U2AF, UAP56, THOC, hnRNPs, and SR and subunits of one downregulated protein Y14 in transgenic plant as compared with the wild type (Fig. 11a, b).

\section{Discussion}

\section{MfEF2 confers cold tolerance with altering proteomic} profiling

A cold responsive $M f E F 2$ from $M$. falcata was identified in this study. MfEF2 showed a high similarity with other plant eEF2s including MtEF2 and AtEF2. Although our knowledge on the role of eEF2 in plant growth and development as well abiotic stress adaptation is limited, an early observation on Arabidopsis mutant los 1-1 reveals an essential role of AtEF2 in cold tolerance. One point mutation of Cys495 residue that is conserved in all plant
eEF-2 proteins in los $1-1$ resulted in reduced cold tolerance [24]. In this study, we found that MfEF2 transcript was induced in response to low temperature, and overexpression of MfEF2 resulted in enhanced freezing and chilling tolerance in transgenic plants. Compared to the wild type, transgenic tobacco plants had higher survival rate after freezing, or had lower levels of ion leakage and ROS accumulation and higher levels of $A$ and $F_{\mathrm{v}} / F_{\mathrm{m}}$ after chilling treatment. Our results in combination with that in los 1-1 suggest that eEF2 confers cold tolerance and $M f E F 2$ is a potential candidate gene used for crop improvement of cold tolerance.

Eukaryotic translation elongation factor-2 functions to mediate the translocation step in peptide chain elongation during protein synthesis. Although protein synthesis in the mutant los $1-1$ is not altered at room temperature, new proteins synthesis is blocked under

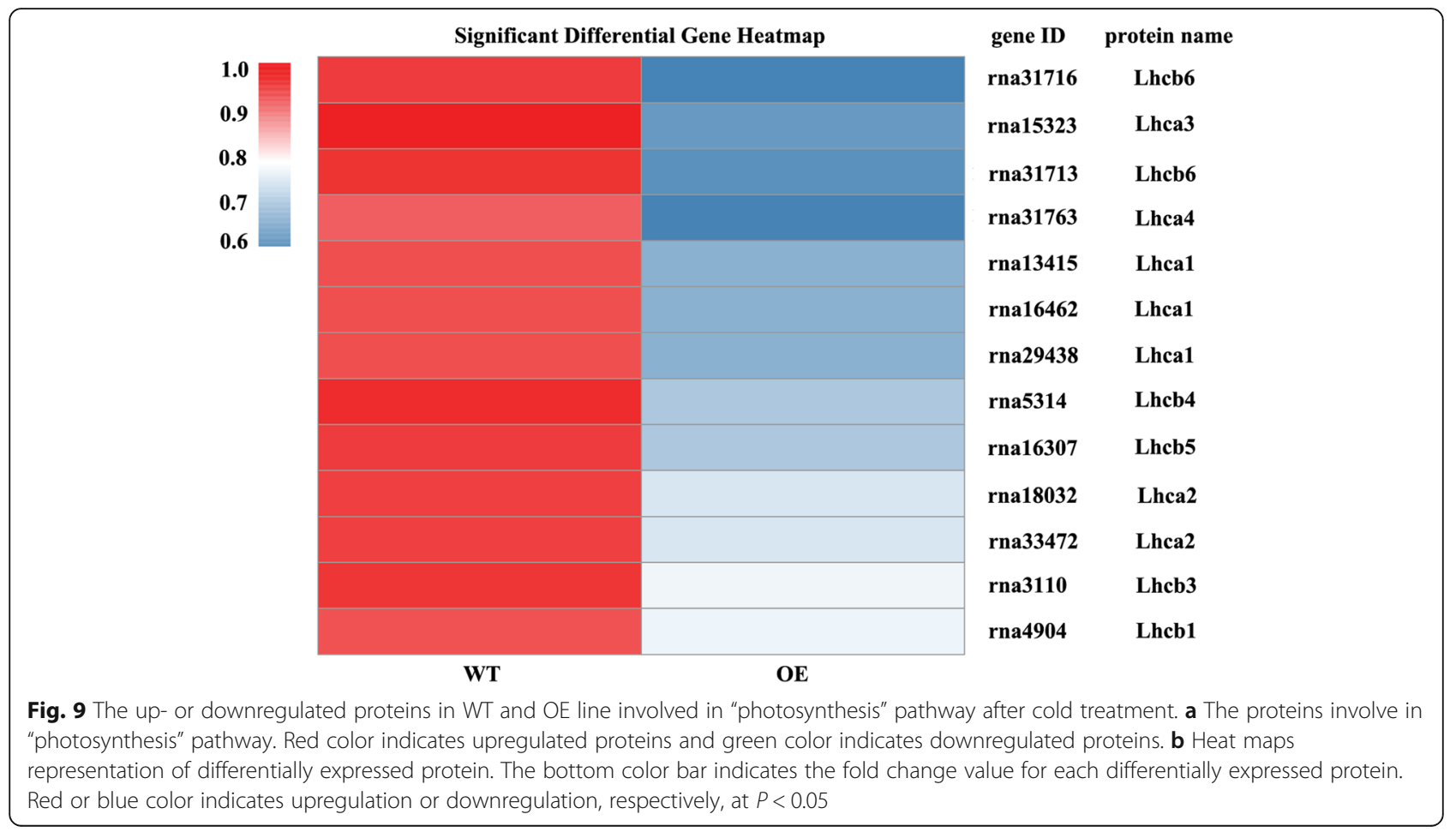


$\mathbf{a}$

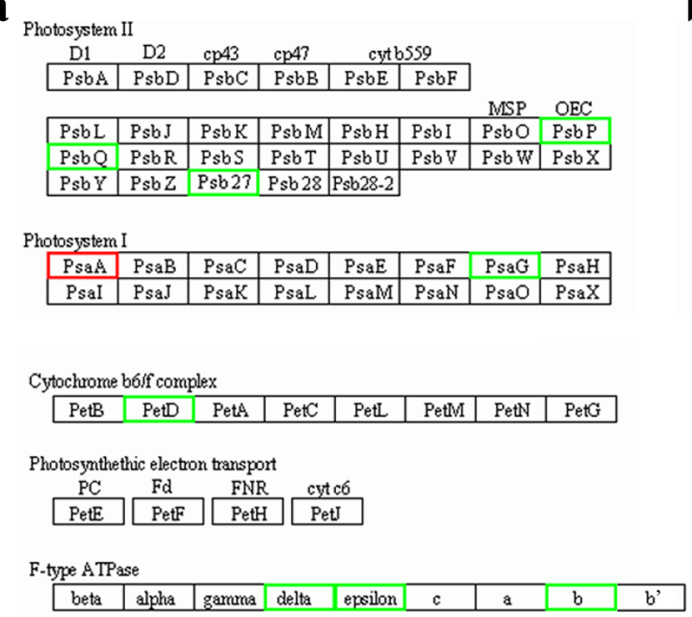

b

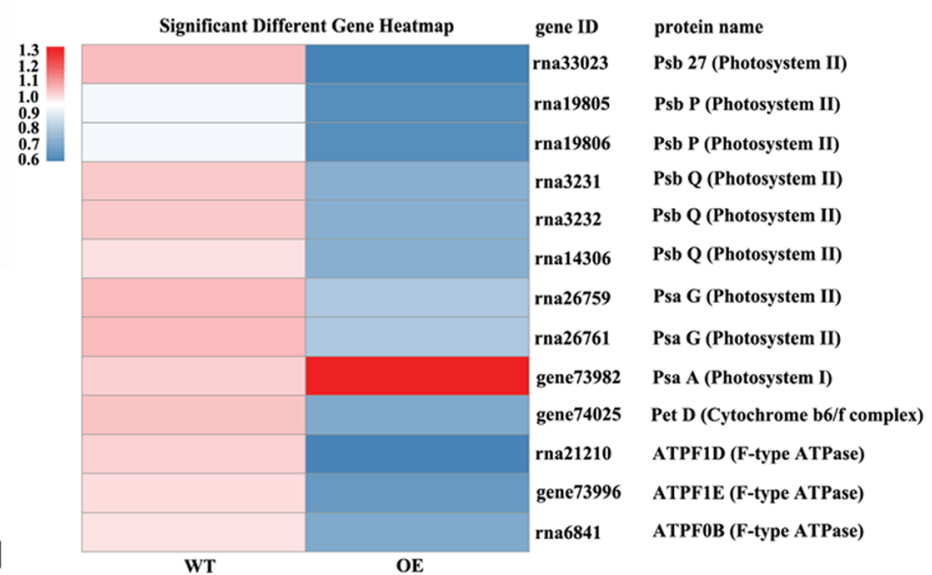

Fig. 10 Heat maps showing the up- or downregulated proteins in WT and OE line involved in "photosynthesis-antenna protein" pathway after cold treatment. The bottom color bar indicates the fold change value for each differentially expressed protein. Red or blue color indicates upregulation or downregulation, respectively, at $P<0.05$

low temperature [24]. In the present study, 336 DEPs including 181 up-regulated proteins and 155 down -regulated proteins were identified in a transgenic line as compared with the wild type after low temperature treatment, indicating that MfEF2 expression altered proteomic profiling under low temperature condition.
Photosynthesis related proteins were regulated by expression of MfEF2 under low temperature condition Photosynthesis is sensitive to low temperature [25]. Proteomics analysis revealed that many cold responsive proteins were related to chloroplast physiology and function in Thellungiella, rice and maize [26-28]. Light

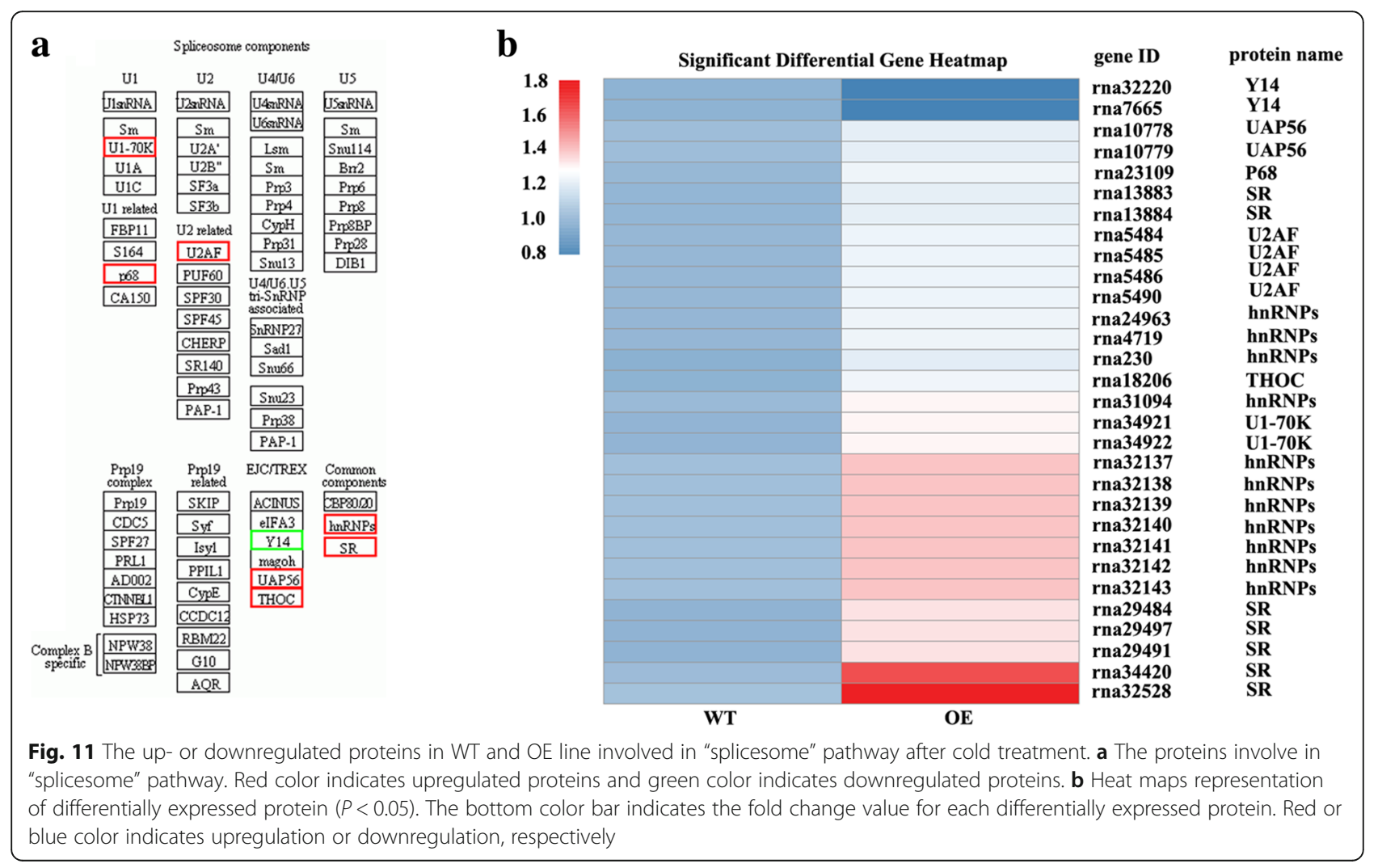


energy is captured and transmited by LHC rapidly to the photochemical reaction center of PSI and PSII located on thylakoid membranes to form energy carrying molecules ATP and NADPH [29], while ATP and NADPH are used for carbonhydrate formation during $\mathrm{CO}_{2}$ accimilation through Calvin-Benson cycle in chloroplast. In higher plants, LHCI in PSI antenna complex is composed of four different subunits named as Lhcal to Lhca4 [30], while LHCII is composed of six different subunits (Lhcb1 to Lhcb6) in PSII antenna complexes [31]. All subunits of LHCI and LHCII except for Lhcb2 were down-regulated in transgenic plants as compared with the wild type under low temperature. The significant suppression of photosynthesis-related genes under cold stress has been observed in Arabidopsis and barley [32, 33]. Transcriptome analysis revealed that many genes encoding photosynthesis-antenna proteins (including Lhca1, Lhca2, Lhca4, Lhcb1, Lhcb4, Lhcb6) were significantly down-regulated in Lotus japonicus after cold treatment [34]. Expression of the genes encoding PSbP, PsbQ, PsbR, PsbW was suppressed in Lotus japonicus [35] in response to low temperature. Likely, PsbP, PsbQ, and Psb27, the subunits in the core complex of PSII, as well as PsaG, the subunit in the core complex of PSI, were down-regulated in transgenic plants compared with the wild type. The down regulation of LHC was an adaptation effect for reduced absorption of light energy by plants when light energy could not be used effectively under low temperature. The two photosystems are functionally connected by the plastoquinone (PQ) and cytochrome b6/f, which catalyze the building of the transthylakoid proton gradient that is dissipated for ATP synthesis by chloroplast ATP synthase [36]. The down-regulated expression of PetD, ATPF1E, ATPF1D and ATPFOB, which was consistent with that of LHC and core complex of PSII and PSI, would lead to decreased ATP synthesis in transgenic plants as compared with the wild type under low temperature.

Exposure to low temperature decreases activities of the enzymes involving in Calvin-Benson cycle, which leads to reduced utilization of absorbed light energy for $\mathrm{CO}_{2}$ assimilation and increased production of ROS via the water-water cycle [37]. Down regulation of the LHC proteins may lead to decreased capacity to capture sun light and reduced photochemical reaction in transgenic tobacco under low temperature conditions, which result in reduced production of ROS and oxidative injury on plant cells. This was confirmed by the less accumulated $\mathrm{H}_{2} \mathrm{O}_{2}$ in transgenic tobacco plants than in the wild type under low temperature. In addition, transgenic plants had higher levels of NPQ than the wild type. NPQ is one of the major photoprotective mechanisms to dissipate excitation energy absorbed by the light-harvesting antenna of photosystem II (PSII) as heat for protection of photosynthetic apparatus against damage [38]. Thus, the increased cold tolerance in MfEF2 trasngenic plants was associated with the reduced expression of photosynthesis related proteins.

\section{MfEF2 regulates protein levels involving in splicesome under low temperature condition}

A total of thirty DEPs involving in splicesome were observed in transgenic tobacco as compared with the wild type in the present study. The DEPs belong to subunits of seven upregulated proteins including U1-70 K, p68, U2AF, hnRNPs, SR, UAP56, and THOC and one downregulated protein Y14. Spliceosome is a multi-megadalton ribonucleoprotein (RNP) complex catalyzing nuclear pre-mRNA splicing. Alternative splicing is frequently associated with regulation of cold responsive genes in plants $[39,40]$. A pre-mRNA splicing factor STABILIZED1 (STA1) in Arabidopsis is strongly upregulated by cold stress, while the mutant sta1 shows mis-splicing of RNAs under cold stress with extremely cold sensitive, suggesting that pre-mRNA splicing is essential for cold tolerance [41]. The serine/arginine-rich (SR) proteins are involved in splicing control by promoting alternative splicing of their own transcripts as well as other gene products [42]. Most of the mRNAs of SR genes in Arabidopsis undergo alternative splicing following cold, heat, salt stress [40, 43, 44]. In addition, alternative splicing of the circadian clock gens depends on temperature, which is associated with the interaction of the conserved SNW/Ski-interacting protein (SKIP) domain-containing proteins with the spliceosomal splicing factor SR45 [45]. Nevertheless, our data suggested that the enhanced cold tolerance in MfEF2 trasngenic tobacco plants is associated with splicesome. However, the information on alternative splicing profiles and the target splicing genes responsive to cold as affected by MfEF2 remain to be further investigated. A genome-wide analysis of alternative pre-mRNA splicing between the wild type and MfEF2 overexpression plants based on full-length cDNA sequences will be conducted in the future.

\section{Conclusions}

$M f E F 2$ transcript was induced in response to low temperature in M. falcata. Overexpression of MfEF2 resulted in enhanced cold tolerance with reduced production of ROS. Hundreds of DEPs in transgenic plants versus the wild type under low temperature were enriched in multiple pathways, while many of them are involved in photosynthesis as subunits of PS I and PSII as well as LHC showing downregulation and spliceosome showing upregulation in transgenic plants as compared with the wild type. It is suggested that the enhanced cold tolerance in MfEF2 transgenic tobacco was associated with downregulation of photosynthesis 
related DEPs, which leads to reduced capacity to capture of sun light and photochemical reaction but increased $N P Q$ to dissipate excitation energy as heat and thus results in reduced ROS production for protectin of plants against oxidative injury under low temperature, and upregulation of the DEPs involving in splicesome, which promotes alternative splicing of pre-mRNA of cold responsive genes.

\section{Methods}

\section{Plant growth}

Medicago falcata and the homozygous lines $\left(\mathrm{T}_{3}\right)$ of transgenic tobacco plants overexpressing MfEF2 in combination with the wild type were grown in $15-\mathrm{cm}$ diameter plastic pots containing a mixture of peat and perlite $(3: 1, \mathrm{v} / \mathrm{v})$ in greenhouse with temperature ranging from 20 to $28^{\circ} \mathrm{C}$ under natural light. Two-month-old $M$. falcata plants were used for cold treatment at $5{ }^{\circ} \mathrm{C}$ for $4 \mathrm{~d}$ for gene expression in response to cold, while two-month-old tobacco plants were used for freezing or chilling treatment for assessment of cold tolerance. Medicago falcata seeds were sent from Chinese Academy of Agricultural Sciences (Beijing 100,193, China), while the seeds of tobacco were reproduced and kept in our laboratory after they were originally sent from Guangdong Academy of Agricultural Sciences (Guangzhou 510,641, China).

\section{RT-PCR and qRT-PCR}

Total RNA was extracted using TRIzol reagent (Invitrogen) according to the manufacturer's instructions. The cDNA was synthesized from $1 \mu \mathrm{g}$ of total RNA, using the PrimeScript RT reagent Kit with gDNA Eraser (Takara, Japan). For cloning of $M f E F 2$, forward primer RT77 (5' -CTAGTCAAGATGGTGAAGTTCACAG-3') and reverse primer RT78 (5'-CAGTTTTCATAACAGCCAAGTACAT-3') were designed after an assembly of EST sequences using SeqMan (DNASTAR Inc., Madison, WI, USA) based on EF2 sequence data from the GenBank. RT-PCR was conducted in a reaction mixture containing the cDNA, dNTPs, primers RT77 and RT78, and Ex Taq DNA polymerase (Takara, Dalian, China). MfEF2 cDNA and the deduced amino acid sequences were analyzed using DNAMAN software (Lynnon Biosoft, Vaudreuil, Quebec, Canada). EF2 transcript was analyzed uisng qRT-PCR in MiniOption Real-Time PCR System (Bio-Rad, Hercules, CA) following the manufacturer's instructions. The PCR reaction mix was consisted of diluted cDNA as template, $200 \mathrm{nM}$ forward and reverse primers, and $5 \mu$ SYBR Premix Ex Taq (Takara, Dalian, China). Parallel reactions to amplify actin1 were used to normalize the amount of template. ZG1753 (5'-GCAC TCCGTATTACTGATGG-3') and ZG1754 (5' ${ }^{\prime}$-TCTG GTATGCCTCCTCTC-3') were used as forward and reverse primers of MfEF2, while ZG1613 (5'-ATTC
ACGAGACCACCTAC-3') and ZG1614 (5'-GAGC CACAACCTTAATCTTC-3') were used for amplification actin respectively. Relative expression was calculated by $2^{-\Delta \Delta C t}$. The primer specifcity was validated by melting profles, showing a single product specifc melting temperature. All PCR effciencies were above 95\%.

\section{Transgenic tobacco generation and DNA and RNA blot hybridization}

The coding sequence of MfEF2 was cloned into the pBI121 binary vector to construct an expressing plasmid pBI-MfEF2. Transgenic plants was generated using Agrobacterium tumefaciens-mediated transformation after selection by kanamycin as previously described [11]. Gnomic DNA was isolated using CTAB. Ten $\mu \mathrm{g}$ was used for digestion with $\mathrm{Xba}$ I overnight (Takara Bio Inc. Dalian, China) for DNA blot analysis, while $20 \mu$ g total RNA was used for RNA blot analysis. NPTII and MfEF2 gene were labeled as probe using $\left[\alpha-{ }^{32} \mathrm{P}\right] \mathrm{dCTP}$ for DNA and RNA blot hybridization, respectively, using the standard procesure. Hybridization signals were detected on Typhoon Trio (General Electric Company, Fairfield, CT).

\section{Cold tolerance assay}

Survival rate was determined to evaluate freezing tolerance as described previously [17]. Fifteen to twenty two-month-old tobacco plants in each pot were placed in a growth chamber with temperature decreasing from 25 to $-3{ }^{\circ} \mathrm{C}$ linearly within $6 \mathrm{~h}$ and maintained for $10 \mathrm{~h}$ under light of $700 \mu \mathrm{mol}$ photon $\mathrm{m}^{-2} \mathrm{~s}^{-1}$. Five pots of plants were employed as replicates in each experiment. Plant survival rate was calculated, and photos were taken 5 days after plants were moved to room temperature for recovery. For chilling treatment, tobacco plants were placed in a growth chamber at $2{ }^{\circ} \mathrm{C}$ for $3 \mathrm{~d}$ with a 12-h photoperiod under light of $700 \mu \mathrm{mol}$ photon $\mathrm{m}^{-2} \mathrm{~s}^{-1}$. Ion leakage was measured by reading conductivity (C1) $12 \mathrm{~h}$ after placing leaflets in to tubes and followed by addition of $10 \mathrm{ml}$ deionized water in each tube. Tubes were then heated in a boiling water bath for $20 \mathrm{~min}$ before measuring the total potential conductivity $(C 2)$ at room temperature. The percentage of ion leakage was calculated as $(C 1 / C 2) * 100 . F_{\mathrm{v}} / F_{\mathrm{m}}, q_{\mathrm{p}}$ and $N P Q$ were measured from five plants of each line using a pulse-modulated fluorometer (Model FMS-2, Hansatech Instruments) according to the manufacturer's instructions [46], while net photosynthetic rate $(A)$ was determined from ten plants using using portable photosynthesis system (model LI-6400; LI-COR Biosciences, Lincoln, NE) according to the manufacturer's instructions [14]. 


\section{$\mathrm{H}_{2} \mathrm{O}_{2}$ detection}

Hydrogen peroxide was visualized by staining with 3 , 3-diaminobenzidine (DAB). Plant leaves were excised and supplied with solution of $1 \mathrm{mg} / \mathrm{mL}$ DAB in Tris- $\mathrm{HCl}$ buffer (pH 6.5) containing 0.01\% Triton X-100. The samples were incubated at room temperature for $1 \mathrm{~h}$ in the dark, followed by decoloring in boiling ethanol for 20 min as described previously [17].

\section{Protein extraction, digestion, iTRAQ labeling and LC-MS/ MS analysis}

Total proteins were extracted using the cold acetone method. Leaves were sampled from the transgenic line (54) and the wild type after treated for $48 \mathrm{~h}$ at $3{ }^{\circ} \mathrm{C}$. The leaf samples were powdered with liquid nitrogen, followed by extraction in Lysis buffer consisting of $8 \mathrm{M}$ urea, 2\% SDS and 1× Protease Inhibitor Cocktail (Roche Ltd. Basel, Switzerland) with sonication on ice for 30 $\min$. The homogenate was centrifuged at $12000 \mathrm{rpm}$ for $20 \mathrm{~min}$ at $4^{\circ} \mathrm{C}$. The supernatant was moved into a fresh tube and incubated at $-20{ }^{\circ} \mathrm{C}$ overnight, followed by centrifugation at $25000 \mathrm{~g}$ for $20 \mathrm{~min}$. The precipitate was suspended in pre-cooled acetone and centrifuged as above. This procedure was repeated until the supernatant was completely colorless. After air-dried, the precipitate was incorporated into $8 \mathrm{M}$ Lysis buffer, incubated at room temperature with sonication for $15 \mathrm{~min}$, and then centrifuged as above. Protein quality and concentrations were determined with SDS-PAGE and the Bradford assay. Two biological replicates were prepared for the iTRAQ analysis, which was conducted (Gene Denovo Biotechnology Co., Guangzhou, China) as described before [46].

Protein was digested with Trypsin Gold (Promega, Madison, WI, USA). After the digested samples were dissolved in $500 \mathrm{mM}$ Triethylammonium bicarbonate (TEAB) solution. The wild type and transgenic tobacco plant samples were labeled with iTRAQ tags according to manufacturer's protocol in the iTRAQ 8-plex labelling kit (Applied Biosystems, Foster City, CA, USA). The labeled samples were pooled and dried by vacuum centrifugation.

The iTRAQ-labeled peptide mixtures were eluted and then fractionated by high $\mathrm{pH}$ separation. The peptides were eluted as follows: from 5 to $45 \%$ buffer B ( $20 \mathrm{mM}$ ammonium formate in $80 \% \mathrm{ACN}, \mathrm{pH} 10.0)$ in $40 \mathrm{~min}$. Fifteen fractions were collected and dried in a vacuum concentrator. Peptide fractions were resuspended in $30 \mu$ solution $\mathrm{C}$ (water with $0.1 \%$ formic acid), separated by nanoLC, and analyzed by on-line electrospray tandem mass spectrometry. The experiments were performed on an Easy-nLC 1000 system (Thermo Fisher Scientific, MA, USA) connected to a Orbitrap Fusion Tribrid mass spectrometer (Thermo Fisher Scientific, MA, USA) equipped with an online nano-electrospray ion source.
The fusion mass spectrometer was operated in the data-dependent acquisition mode to switch automatically between MS and MS/MS acquisition. Full-scan MS spectra (m/z 350-1550) were acquired with a mass resolution of $120 \mathrm{~K}$, followed by sequential high energy collisional dissociation (HCD) MS/MS scans with a resolution of $30 \mathrm{~K}$. The isolation window was set as 1.6 $\mathrm{Da}$. The AGC target was set as 400,000. MS/MS fixed first mass was set at 110. In all cases, one microscan was recorded using dynamic exclusion of $45 \mathrm{~s}$.

\section{Protein identification and quantification}

Raw data files from LC-MS/MS were converted into MGF (MASCOT generic format) files with Proteome Discovery 1.2 (Thermo, Pittsburgh, PA, USA). Proteins were identified using the Mascot search engine (Matrix Science, London, UK; version 2.5.1). Mascot database was set up for protein identification using Nicotiana tabacum reference transcriptome (https://www.ncbi.nlm. nih.gov/genome/?term=tobacco). Protein quantification was carried out in those proteins identified in all the samples with unique spectra $\geq 2$. The Mascot search results were averaged using medians and quantified. Proteins with fold change in a comparison $>1.2$ or $<0.83$ and unadjusted significance level $P<0.05$ were considered differentially expressed [47].

\section{Bioinformatics analysis}

Differentially expressed proteins were classified and identified using the Gene Ontology (GO) (http://www. geneontology.org) and the Kyoto Encyclopedia of Genes and Genomes (KEGG) (http://www.genome.jp/kegg/ or http://www.kegg.jp/). Significant pathway enrichment was examined with the hypergeometric test. A $P$-value $\leq 0.05$ was used as the threshold to determine the significant enrichments of GO and KEGG pathways.

\section{Additional files}

Additional file 1: Figure S1. Basic information statistics of Protein identification (PDF 5 kb) (PDF 4 kb)

Additional file 2: Table S1. List of the total 2939 proteins identified in this study (XLS $3170 \mathrm{~kb})$ (XLS $3169 \mathrm{~kb})$

Additional file 3: Figure S2. Mass distribution of the identified protein (PDF $5 \mathrm{~kb}$ ) (PDF $4 \mathrm{~kb}$ )

Additional file 4: Table S2. List of upregulated and downregulated proteins identified and quantified by $\mathrm{iTRAQ}$ analysis in transgenic plant versus the wild type (XLS $469 \mathrm{~kb})$ (XLS $468 \mathrm{~kb}$ )

\section{Abbreviations}

A: Net photosynthetic rate; CBF: CRT binding factor; COR: Cold regulated; DEPs: Differentially expressed proteins; eEF-2: Eukaryotic translation elongation factor-2 (eEF-2); ERF: Ethylene responsive factor; $F_{\mathrm{v}} / F_{\mathrm{m}}$ : Maximum photochemical efciency of PSII; GolS: Galactinol synthase; INT-like: Myoinositol transporter-like; iTRAQ: Isobaric tags for relative and absolute quantification; LHC: Light harvesting chlorophyll protein complex; MIPS: Myoinositol phosphate synthase; NPQ: Nonphotochemical quenching; ORF: Open 
reading frame; PIP: Plasma membrane intrinsic protein; PS: Photosystem; $q_{p}$ : Photochemical quenching; ROS: Reactive oxygen species; SAMS: Sadenosylmethionine synthetase; SSH: Suppression subtractive hybridization; TIL: Temperature induced lipocalin

\section{Funding}

This work was financially supported by the National Natural Science Foundation of China (31472142, 31672481).

\section{Availability of data and materials}

All datasets supporting the results of this study are included in the article and the additional files.

\section{Authors' contributions}

HS conducted proteomic analysis; SH cloned MfEF2 and generated transgenic plants; XH analyzed cold tolerance. HS wrote the paper; ZG and $S L$ designed the study and analyzed the data. ZG revised the manuscript. All authors read and approved the final manuscript.

\section{Ethics approval and consent to participate}

Not applicable.

\section{Consent for publication}

Not applicable.

\section{Competing interests}

The authors declare that they have no competing interests.

\section{Publisher's Note}

Springer Nature remains neutral with regard to jurisdictional claims in published maps and institutional affiliations.

\section{Author details}

${ }^{1}$ College of Grassland Science, Nanjing Agricultural University, Nanjing 210095, China. ${ }^{2}$ State Key Laboratory for Conservation and Utilization of Subtropical Agro-bioresources, College of Life Sciences, Guangdong Engineering Research Center for Grassland Science, South China Agricultural University, Guangzhou 510642, China.

\section{Received: 22 November 2018 Accepted: 9 May 2019}

\section{Published online: 27 May 2019}

\section{References}

1. Knight MR, Knight $\mathrm{H}$. Low-temperature perception leading to gene expression and cold tolerance in higher plants. New Phytol. 2012;195:737-51.

2. Chinnusamy $V$, Zhu J, Zhu JK. Cold stress regulation of gene expression in plants. Trends Plant Sci. 2007;12:444-51.

3. Medina J, Catala R, Salinas J. The CBFs: three arabidopsis transcription factors to cold acclimate. Plant Sci. 2011;180:3-11.

4. Shi Y, Ding Y, Yang S. Cold signal transduction and its interplay with phytohormones during cold acclimation. Plant Cell Physiol. 2015;56:7-15.

5. Chinnusamy V, Ohta M, Kanrar S, Lee BH, Hong X, Agarwal M, et al. ICE1: a regulator of cold-induced transcriptome and freezing tolerance in Arabidopsis. Genes Dev. 2003;17:1043-54.

6. Zarka DG, Vogel JT, Cook D, Thomashow MF. Cold induction of Arabidopsis CBF genes involves multiple ICE (inducer of CBF expression) promoter elements and a cold-regulatory circuit that is desensitized by low temperature. Plant Physiol. 2003;133:910-8.

7. Thomashow MF. Molecular basis of plant cold acclimation: insights gained from studying the CBF cold response pathway. Plant Physiol. 2010;154:571-7.

8. Bolouri-Moghaddam MR, Le RK, Xiang L, Rolland F, dEW V. Sugar signalling and antioxidant network connections in plant cells. FEBS J. 2010;277:2022-37.

9. Suzuki N, Mittler R. Reactive oxygen species and temperature stresses: a delicate balance between signaling and destruction. Physiol Plant. 2006; 126:45-51.

10. Pennycooke JC, Cheng H, Stockinger EJ. Comparative genomic sequence and expression analyses of Medicago truncatula and alfalfa subspecies falcata COLD-ACCLIMATION-SPECIFIC genes. Plant Physiol. 2008;146:1242-54.

11. Tan J, Wang C, Xiang B, Han R, Guo Z. Hydrogen peroxide and nitric oxide mediated cold- and dehydration-induced myo-inositol phosphate synthase that confers multiple resistances to abiotic stresses. Plant Cell Environ. 2013; 36:288-99.

12. Riday H, Brummer EC. Forage yield heterosis in alfalfa. Crop Sci. 2002;42:716-23.

13. Riday H, Brummer EC, Campbell TA, Luth D, Cazcarro PM. Comparisons of genetic and morphological distance with heterosis between Medicago sativa subsp sativa and subsp falcata. Euphytica. 2003;131:37-45.

14. Zhuo C, Wang T, Lu S, Zhao Y, Li X, Guo Z. A cold responsive galactinol synthase gene from Medicago falcata (MfGo/S1) is induced by myo-inositol and confers multiple tolerances to abiotic stresses. Physiol Plant. 2013;149:67-78.

15. Sambe MAN, He X, Tu Q, Guo Z. A cold-induced myo-inositol transporterlike gene (MfINT-like) confers tolerance to multiple abiotic stresses in transgenic tobacco plants. Physiol Plant. 2015;153:355-64.

16. Guo Z, Tan J, Zhuo C, Wang C, Xiang B, Wang Z. Abscisic acid, $\mathrm{H}_{2} \mathrm{O}_{2}$ and nitric oxide interactions mediated cold-induced S-adenosylmethionine synthetase in Medicago sativa subsp. falcata that confers cold tolerance through up-regulating polyamine oxidation. Plant Biotech J. 2014;12:601-12.

17. He X, Sambe MA, Zhuo C, Tu Q, Guo Z. A temperature induced lipocalin gene from Medicago falcata (MfTIL1) confers tolerance to cold and oxidative stress. Plant Mol Biol. 2015;87:645-54.

18. Zhuo C, Wang T, Guo Z, Lu S. Overexpression of MfPIP2-7 from Medicago falcata promotes cold tolerance and growth under $\mathrm{NO}_{3}{ }^{-}$deficiency in transgenic tobacco plants. BMC Plant Biol. 2016;16:138.

19. Zhuo C, Liang L, Zhao Y, Guo Z, Lu S. A cold responsive ethylene responsive factor from Medicago falcata confers cold tolerance by upregulation of polyamine turnover, antioxidant protection, and proline accumulation. Plant Cell Environ. 2018:41:2021-32

20. Pang C, Wang C, Chen H, Guo Z, Li C. Transcript profiling of cold responsive genes in Medicago falcata. In: Yamada T, Spangenberg G, editors. Molecular breeding of forage and turf. New York: Springer; 2019. p. 141-9.

21. Jørgensen $R$, Merrill $A R$, Andersen GR. The life and death of translation elongation factor 2. Biochem Soc T. 2006;34:1-6.

22. Caster SZ, Castillo K, Sachs MS, Bell-Pedersen D. Circadian clock regulation of mRNA translation through eukaryotic elongation factor eEF-2. Proc Natl Acad Sci U S A. 2016;113:9605-10.

23. Knight JRP, Bastide A, Roobol A, Roobol J, Jackson TJ, Utami W, et al. Eukaryotic elongation factor 2 kinase regulates the cold stress response by slowing translation elongation. Biochem J. 2015;465:227-38.

24. Guo Y, Xiong L, Ishitani M, Zhu JK. An Arabidopsis mutation in translation elongation factor 2 causes superinduction of CBF/DREB1 transcription factor genes but blocks the induction of their downstream targets under low temperatures. Proc Natl Acad Sci U S A. 2002;99:7786-91.

25. Ruelland E, Vaultier MN, Zachowski A, Hurry V. Cold signalling and cold acclimation in plants. Bot Res. 2009;49:36-149.

26. Gao F, Zhou Y, Zhu W, Li X, Fan L, Zhang G. Proteomic analysis of cold stress-responsive proteins in Thellungiella rosette leaves. Planta. 2009;230: 1033-46.

27. Hashimoto M, Komatsu S. Proteomic analysis of rice seedlings during cold stress. Proteomics. 2007;7:1293-302.

28. Wang X, Shan X, Ying W, Su S, Li S. Liu H, et al. iTRAQ-based quantitative proteomic analysis reveals new metabolic pathways responding to chilling stress in maize seedlings. J Proteomic. 2016;146:14-24.

29. Nelson N, BenShem A. The complex architecture of oxygenic photosynthesis. Nat Rev Mol Cell Biol. 2004;5:971-82.

30. Scheller HV, Jensen PE, Haldrup A, Lunde C, Knoetzel J. Role of subunits in eukaryotic photosystem I. Biochim Biophys Acta. 2001;1507:41-60.

31. Croce R, Van AH. Light-harvesting and structural organization of photosystem II: from individual complexes to thylakoid membrane. J Photoch Photobio B. 2011;104:142-53.

32. Hannah MA, Heyer AG, Hincha DK. A global survey of gene regulation during cold acclimation in Arabidopsis thaliana. PLoS Genet. 2005;1:e26.

33. Svensson JT, Crosatti C, Campoli C, Bassi R, Stanca AM, et al. Transcriptome analysis of cold acclimation in barley Albina and Xantha mutants. Plant Physiol. 2006;141:257-70.

34. Calzadilla PI, Maiale SJ, Ruiz OA, Escaray FJ. Transcriptome response mediated by cold stress in Lotus japonicus. Front Plant Sci. 2016;7:374.

35. Liu H, Ouyang B, Zhang J, Wang T, Li H, Zhang Y, et al. Differential modulation of photosynthesis, signaling, and transcriptional regulation between tolerant and sensitive tomato genotypes under cold stress. PLoS One. 2012;7(11):e50785.

36. Dekker JP, Boekema EJ. Supramolecular organization of thylakoid membrane proteins in green plants. BBA-Bioenergetics. 2005;1706:12-39. 
37. Kumar PA, Parry MAJ, Mitchell RAC, Ahmad A, Abrol YP. Photosynthesis and nitrogen-use efficiency. In: Foyer $\mathrm{CH}$, Noctor $\mathrm{G}$, editors. Photosynthetic nitrogen assimilation and associated carbon and respiratory metabolism. Advances in photosynthesis research. Amsterdam: Kluwer; 2002. p. 23-34.

38. Niyogi KK, Truong TB. Evolution of flexible non-photochemical quenching mechanisms that regulate light harvesting in oxygenic photosynthesis. Curr Opin Plant Biol. 2013;16:307-14.

39. lida K, Seki MT, Sakurai T, Satou M, Akiyama K, Toyoda T, Konagaya A, Shinozaki K. Genome-wide analysis of alternative pre-mRNA splicing in Arabidopsis thaliana based on full-length CDNA sequences. Nucleic Acids Res. 2004;32:5096-103.

40. Palusa SG, Ali GS, Reddy ASN. Alternative splicing of pre-mRNAs of Arabidopsis serine/arginine-rich proteins: regulation by hormones and stresses. Plant J. 2007:49:1091-107.

41. Lee BH, Kapoor A, Zhu J, Zhu JK. STABILIZED1, a stress-upregulated nuclear protein, is required for pre-mRNA splicing, mRNA turnover, and stress tolerance in Arabidopsis. Plant Cell. 2006;18:1736-49.

42. Wollerton MC, Gooding C, Wagner EJ, Garcia-Blanco MA, Smith CW. Autoregulation of polypyrimidine tract binding protein by alternative splicing leading to nonsense-mediated decay. Mol Cell. 2004;13:91-100,

43. Mazzucotelli E, Mastrangelo AM, Crosatti C, Guerra D, Stanca M, Cattivelli L. Abiotic stress response in plants: when post-transcriptional and posttranslational regulations control transcription. Plant Sci. 2008;174:420-31.

44. Schindler S, Szafranski K, Hiller M, Ali GS, Palusa SG, Backofen R, et al. Alternative splicing at NAGNAG acceptors in Arabidopsis thaliana SR and SRrelated protein-coding genes. BMC Genomics. 2008:9:159.

45. Wang X, Wu F, Xie Q, Wang H, Wang Y, Yue Y, Gahura O, Ma S, Liu L, Cao Y, Jiao Y, Puta F, McClung CR, Xu X, Ma L. Skip is a component of the spliceosome linking alternative splicing and the circadian clock in Arabidopsis. Plant Cell. 2012;24:3278-95.

46. Chen Z, Qin C, Lin L, Zeng X, Zhao Y, He S, Lu S, Guo Z. Overexpression of yeast arabinono-1,4-lactone oxidase gene (ALO) increases tolerance to oxidative stress and Al toxicity in transgenic tobacco plants. Plant Mol Biol Rep. 2015;33:806-18

47. Shi J, Chen Y, Xu Y, Ji D, Chen C, Xie C. Differential proteomic analysis by iTRAQ reveals the mechanism of pyropia haitanensis responding to high temperature stress. Sci Rep. 2017;7:44734.

Ready to submit your research? Choose BMC and benefit from:

- fast, convenient online submission

- thorough peer review by experienced researchers in your field

- rapid publication on acceptance

- support for research data, including large and complex data types

- gold Open Access which fosters wider collaboration and increased citations

- maximum visibility for your research: over $100 \mathrm{M}$ website views per year

At $\mathrm{BMC}$, research is always in progress.

Learn more biomedcentral.com/submissions 